\title{
openheart Transcatheter mitral valve repair: an overview of current and future devices
}

\author{
Ole De Backer (1) , Ivan Wong, ${ }^{1}$ Maurizio Taramasso, ${ }^{2}$ Francesco Maisano, ${ }^{3}$ \\ Olaf Franzen, ${ }^{4}$ Lars Søndergaard ${ }^{1}$
}

\begin{abstract}
- Additional supplemental material is published online only. To view, please visit the journal online (http://dx.doi.org/10.
\end{abstract} 1136/openhrt-2020-001564).

To cite: De Backer 0, Wong I, Taramasso M, et al. Transcatheter mitral valve repair: an overview of current and future devices. Open Heart 2021;8:e001564. doi:10.1136/ openhrt-2020-001564

Received 31 December 2020 Revised 19 February 2021 Accepted 12 April 2021

Check for updates

(c) Author(s) (or their employer(s)) 2021. Re-use permitted under CC BY-NC. No commercial re-use. See rights and permissions. Published by BMJ.

${ }^{1}$ Cardiology, Rigshospitalet, Kobenhavn, Denmark ${ }^{2}$ Department of Cardiothoracic Surgery, University Hospital Zurich, Zurich, Switzerland ${ }^{3}$ Valve Center, Ospedale San Raffaele, Milan, Italy ${ }^{4}$ Hirslanden Klinik im Park, Zurich, Switzerland

Correspondence to Dr Ole De Backer; ole. debacker@gmail.com

\section{ABSTRACT}

The field of transcatheter mitral valve repair (TMVr) for mitral regurgitation (MR) is rapidly evolving. Besides the well-established transcatheter mitral edge-to-edge repair approach, there is also growing evidence for therapeutic strategies targeting the mitral annulus and mitral valve chordae. A patient-tailored approach, careful patient selection and an experienced interventional team is crucial in order to optimise procedural and clinical outcomes. With further data from ongoing clinical trials to be expected, consensus in the Heart Team is needed to address these complexities and determine the most appropriate TMVr therapy, either single or combined, for patients with severe MR.

\section{INTRODUCTION}

Mitral regurgitation (MR) contributes to significant morbidity and mortality. In degenerative MR, medical treatment may be insufficient and cardiac surgery has traditionally been the only effective option. The management of functional MR is more complex and controversial. Functional MR is the result of myocardial disease and treatment is directed at the underlying cardiomyopathy. Guidelinedirected medical therapy (GDMT) and cardiac resynchronisation therapy (CRT) are the cornerstones of treatment, with a focus on the reversal of adverse left ventricular (LV) remodelling. Surgical intervention for functional MR has yielded no difference in clinical outcomes, with high rates of recurrent MR.

The advent of transcatheter mitral valve repair (TMVr) therapies has provided feasible and safe alternatives to medical and surgical treatment-especially for those patients who are not considered suitable candidates for conventional mitral valve surgery. Transcatheter mitral edge-to-edge repair has been the most successful and adopted TMVr therapy to date; with some important new device iterations and improvements in 2020. Besides mitral edge-to-edge repair, there is also growing evidence for therapeutic strategies targeting the mitral annulus and mitral valve chordae (box 1). This review article aims at providing a comprehensive overview of all TMVr devices in clinical use and preclinical evaluation at the end of 2020.

\section{Transcatheter mitral annuloplasty}

The purpose of surgical and transcatheter mitral annuloplasty is to reduce the annular circumference and obtain better coaptation of the mitral leaflets. Mitral annuloplasty techniques using transcatheter approaches can be classified as indirect or direct, based on their relation to the mitral annulus.

Transcatheter indirect mitral annuloplasty methods are based on the parallel relationship of the coronary sinus (CS) to the mitral annulus; the Carillon Mitral Contour System (Cardiac Dimensions, Washington, DC, USA) received CE mark approval and the ARTO system (MVRx, California, USA) was studied in the Mitral Valve Repair Clinical (MAVERIC) CE Mark trial. Direct mitral annuloplasty eliminates some of the limitations of the CS approach but represents a technically more challenging and complex procedural approach. Two systems that come the closest to a surgical mitral annuloplasty are the Cardioband Mitral System (Edwards Lifesciences, California, USA) and the Millipede Mitral Annuloplasty System (Boston Scientific, Massachusetts, USA). Both systems use a transseptal approach with a steerable guide catheter.

Despite the fact that some of these transcatheter mitral annuloplasty technologies were already developed and received approval several years ago, none of these technologies have seen the same diffusion or adoption in daily clinical practice as the MitraClip system (Abbott, Illinois, USA). Not only engineering and procedural challenges but also mixed study results have complicated and impacted the adoption of these technologies in current practice. Also considering the high recurrence rates of functional MR after surgical mitral annuloplasty, future studies will have to 


\section{Box 1 Transcatheter mitral valve repair techniques (2020)}

I. Transcatheter mitral annuloplasty.

IA. Indirect mitral annuloplasty.

- Carillon Mitral Contour System.

ART0 system.

IB. Direct mitral annuloplasty.

- Cardioband Mitral System.

- Millipede Transcatheter Mitral Annuloplasty System.

II. Transcatheter edge-to-edge mitral valve repair.

- MitraClip G4 system.

- PASCAL Transcatheter Valve Repair System.

III. Transcatheter mitral valve chordal repair.

NeoChord.

HARPOON Mitral Valve Repair System.

investigate whether transcatheter mitral annuloplasty will provide sustained echocardiographic and clinical effects or whether these techniques lend themselves more to combined procedures-for example, transcatheter mitral annuloplasty plus edge-to-edge mitral valve repair. To date, only limited data are available on combined procedures; the high cost of such combined procedures is an item which cannot be ignored.

\section{Carillon Mitral Contour System}

The Carillon Mitral Contour System obtained CE approval in 2011 and is indicated for use in patients with functional MR who are symptomatic despite treatment with GDMT and who are presenting with annulus dilatation as primary contributor to the significant MR.

The Carillon Mitral Contour System consists of three components: the sizing catheter, the delivery system and the Carillon implant. The sizing catheter is used to estimate the dimensions of the CS and great cardiac vein (GCV), so that an appropriately sized implant can be selected. The delivery system facilitates percutaneous delivery of the implant, engagement of the locking mechanism, and repositioning or recapture of the implant, if necessary. The Carillon XE2 implant is composed of a distal anchor (positioned in the GCV), proximal anchor (positioned in the CS), ribbon connector (joining the anchors), and proximal and distal crimp tubes (figure 1). The implant is designed to be deployed, tensioned and secured in the coronary vein. The MR reduction is immediate and can be modulated during the procedure in the cathlab. The procedure is performed through the jugular venous access and is usually carried out without general anaesthesia.

Limitations of the Carillon System are (1) the distance between the CS and the mitral annulus, which may limit the therapeutic effectiveness; (2) the risk of compression on the left circumflex coronary artery by the distal anchor-although the device can be repositioned or retrieved, if needed and (3) the Carillon System is not recommended in patients with a CRT device or pacing lead in the CS.
In the randomised sham-controlled REDUCE FMR trial enrolling 120 patients, treatment with the Carillon device was shown to significantly reduce MR volumes $(-7.1 \mathrm{~mL} /$ beat vs $+3.3 \mathrm{~mL} /$ beat in the sham-control group) and LV volumes in symptomatic patients with functional MR receiving GDMT. ${ }^{1}$ Recently published 5-year follow-up data also indicate durable functional improvement and favourable 5-year survival rates following treatment with the Carillon System. ${ }^{2}$ These results supported the CARILLON randomised trial (ClinTrials.Gov: NCT03142152), which is ongoing at 75 sites in Europe and the USA, and is comparing the device to GDMT in 352 patients with functional MR.

\section{ARTO system}

The ARTO system is a transcatheter indirect mitral annuloplasty device which aims to improve mitral leaflet coaptation and decrease functional MR via a 'bridge suture' that connects anchors placed in the GCV and the atrial septum.

Using fluoroscopy, delivery of the ARTO system is accomplished by venous access to the right atrium where two procedural steps are performed: (1) the CS is cannulated from the right jugular vein and a T-bar implant is deployed in the lateral wall via the GCV and (2) an atrial septal implant is deployed through a transseptal puncture. A 'bridge suture' between these two anchors provides the means for inward displacement and subsequent reduction of the mitral annular anteroposterior diameter (figure 2). The bridge length is adjusted to achieve optimal MR reduction. Feasibility of MitraClip treatment after ARTO has been shown, despite presence of the bridge.

Results of the prospective, non-randomised MAVERIC CE Mark trial using the ARTO system in 45 patients with functional MR showed the ARTO system to be safe and effective in decreasing functional MR up to 1-year postprocedure. The primary safety composite endpoint (death, stroke, myocardial infarction, device related surgery, cardiac tamponade, renal failure) at 30 days and 1 year was $4.4 \%$ and $17.8 \%$, respectively. The mitral annular antero-posterior diameter decreased from $41.4 \mathrm{~mm}$ (baseline) to 36.0 and $35.3 \mathrm{~mm}$ at 30 days and 1 year, respectively. Paired results for 36 patients showed that $67 \%$ of patients had MR grade $3+/ 4+$ at baseline vs only $14 \%$ and $8 \%$ of patients at 30 days and 1-year postprocedure. In accordance, $69 \%$ of patients had New York Heart Association (NYHA) Class III-IV symptoms at baseline, decreasing significantly to $25 \%$ and $22 \%$ of patients at 30 days and 1-year post-procedure, respectively. ${ }^{3-6}$ Larger randomised controlled trials (RCTs) studying the safety and efficacy of the ARTO system are needed.

\section{Cardioband Mitral System}

The Cardioband Mitral System is a transcatheter, transseptal adjustable direct mitral annuloplasty device which aims to reduce the annular circumference and improve 


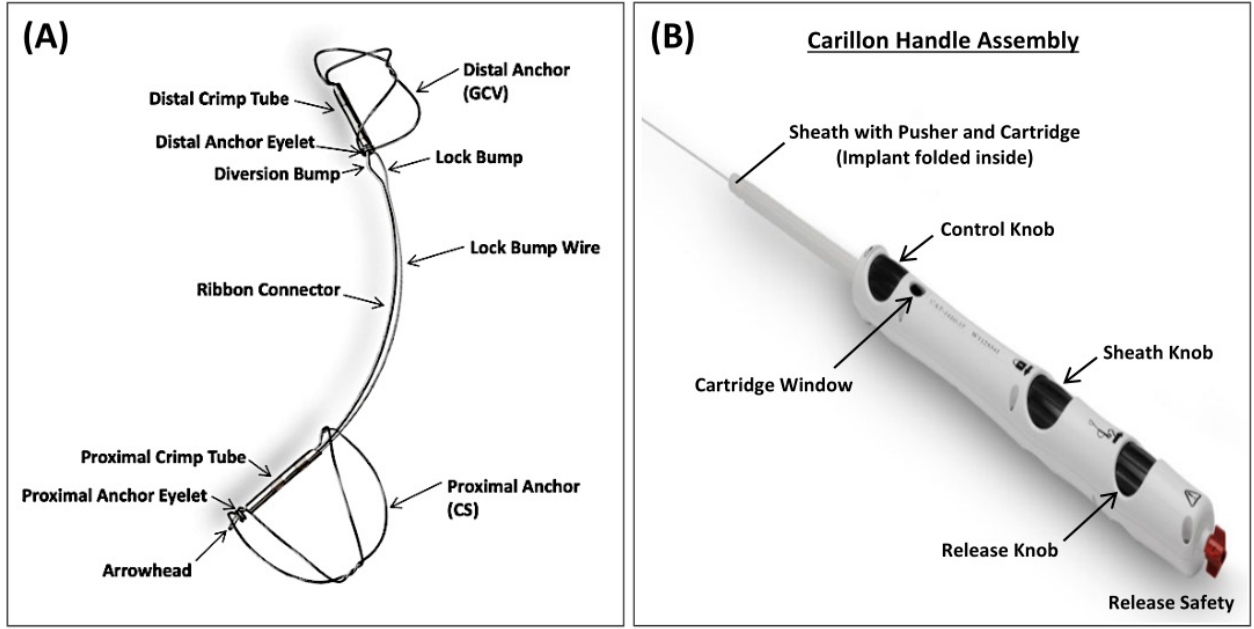

\section{CARILLON Implanted Device Specifications}

\begin{tabular}{ll}
\hline Distal anchor sizes & Length $60 \mathrm{~mm}: 7-12 \mathrm{~mm}$, available in $1 \mathrm{~mm}$ increments \\
& $\begin{array}{l}\text { Length } 70 \mathrm{~mm}: 13-14 \mathrm{~mm} \text {, available in } 1 \mathrm{~mm} \text { increments } \\
\text { Length } 80 \mathrm{~mm}: 7-14 \mathrm{~mm} \text {, available in } 1 \mathrm{~mm} \text { increments }\end{array}$ \\
\hline Proximal anchor sizes & Length $60 \mathrm{~mm}: 16,18,20 \mathrm{~mm}$ \\
& Length $70 / 80 \mathrm{~mm}: 18,20 \mathrm{~mm}$ \\
\hline Material & Nitinol, Titanium \\
\hline
\end{tabular}

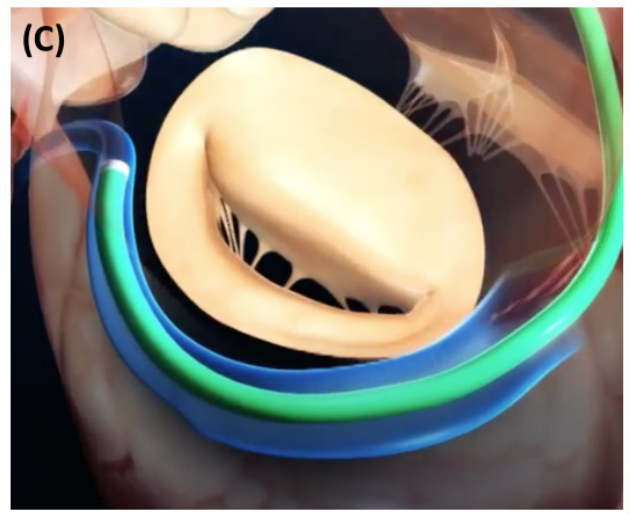

Mitral annulus dilatation before implantation of Carillon ${ }^{\mathrm{TM}}$ device

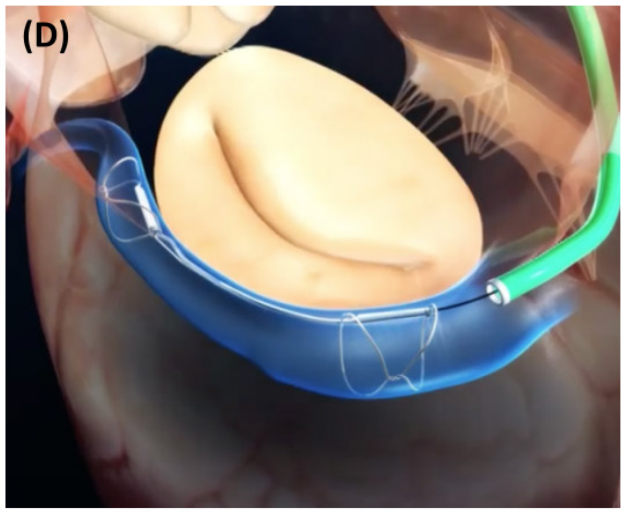

Mitral annulus remodeled with Carillon ${ }^{\mathrm{TM}}$ device

Figure 1 Carillon Mitral Contour System. (A) Components of the Carillon implanted device-the distal and proximal anchor are implanted in the great cardiac vein (GCV) and coronary sinus (CS), respectively. (B) Components of the Carillon Handle Assembly. (C and D) The implant is designed to be deployed, tensioned and secured in the coronary vein; the reduction of the mitral regurgitation is immediate and can be modulated during the procedure. Images courtesy of and provided by Cardiac Dimensions.

mitral leaflet coaptation. The Cardioband implant consists of a polyester sleeve with radiopaque markers at every $8 \mathrm{~mm}$; the sleeve covers the delivery system which deploys the screw anchors. Correct positioning of the first anchor is crucial and multiplanar transesophageal echocardiography (TEE) and 3D-TEE views are necessary to verify correct placement (figure 3 ). The first anchor is placed lateral and as anterior as possible in the mitral annulus; coronary angiography is performed to rule out damage to the left circumflex coronary artery. The anchors are repeatedly placed along the posterior side at the mitral annulus until the implant catheter tip reaches the last anchoring site at the medial side. A contraction wire following the same path as the sleeve is connected to an adjusting spool. Activating the spool cinches the Cardioband device, thereby reducing the mitral annular diameter. Adequate reduction of MR severity is assessed by TEE under beating heart conditions. The implant is available in different sizes.

The Cardioband Mitral System gained CE mark for the treatment of functional MR in 2016. In a single-arm, multicentre prospective study, results obtained in 60 consecutive patients with moderate or severe functional MR treated with the Cardioband System were reported. There were two in-hospital deaths (none devicerelated), one stroke, two coronary artery complications 

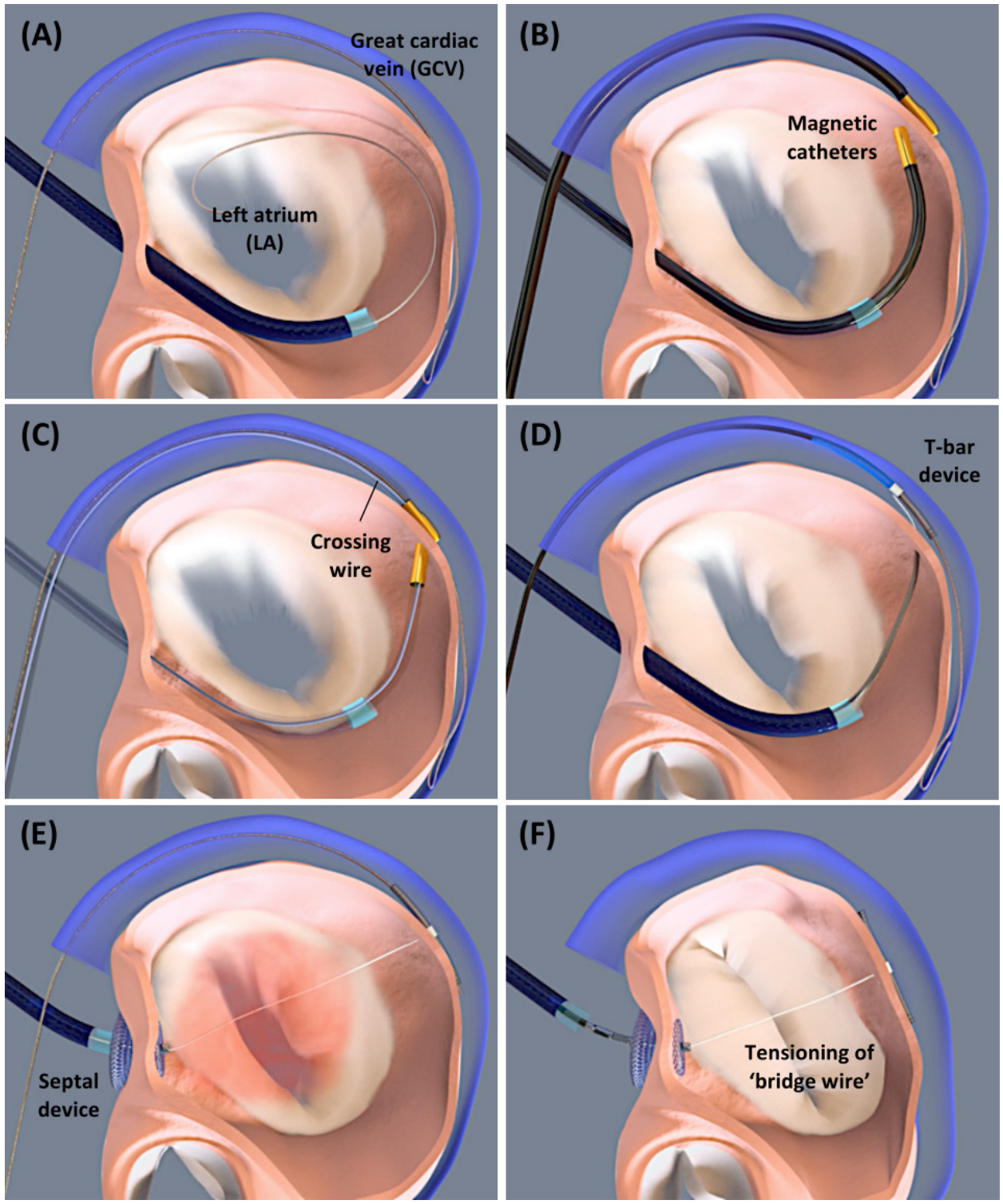

Figure 2 ARTO system. (A) Insertion of a guide wire in the great cardiac vein (GCV) via the right jugular vein and transseptal insertion of a guide wire and $12 \mathrm{Fr}$ sheath into the left atrium (LA). (B) Insertion of GCV and LA magnetic catheters, which should connect at the side of the posterior mitral leaflet. (C) Insertion of the crossing wire from GCV to LA side through the magnetic catheters. (D) Following removal of the magnetic catheters and exchanging the crossing wire with the bridgeextension wire, implantation of the T-bar device in the lateral wall via the GCV. (E) Next, implantation of the septal device. (F) Tensioning of the 'bridge wire' between the T-bar in the GCV and septal anchor, resulting in shortening of the mitral annulus anterior-posterior diameter and mitral regurgitation reduction. Images courtesy of and provided by MVRx.

and one tamponade. Anchor disengagement, observed in 10 patients, resulted in device inefficacy in 5 patients and led to device modification half way through the study to mitigate this issue. Technical, device and procedural successes were $97 \%, 72 \%$ and $68 \%$, respectively. At 1-year, overall survival, survival free of readmission for heart failure and survival free of reintervention (performed in seven patients) were $87 \%, 66 \%$ and $78 \%$, respectively. MR grade at 12 months was $\leq$ grade $2+$ in $61 \%$ of the overall population and in $95 \%$ of the 39 patients who underwent a transthoracic echocardiography at 1 year; but worsened by at least one grade in 11 patients (22\%). The latter suggests some recurrence of functional MR in this population. Functional status
( $79 \%$ vs $14 \%$ in NYHA Class I/II), quality of life and exercise capacity $(+58 \mathrm{~m}$ by $6 \mathrm{MWT})$ improved significantly. ${ }^{7}$ In summary, the Cardioband Mitral System demonstrated reasonable performance and safety; however, a larger RCT is absolutely needed. In the ACTIVE trial, patients will be randomised 2:1 to receive either TMVr with the Cardioband Mitral System plus GDMT versus GDMT alone.

\section{Millipede Transcatheter Mitral Annuloplasty System}

The Millipede System is a transcatheter, transseptal direct mitral annuloplasty device currently under development and investigation. The technology has demonstrated proof-of-concept in more than 20 human 

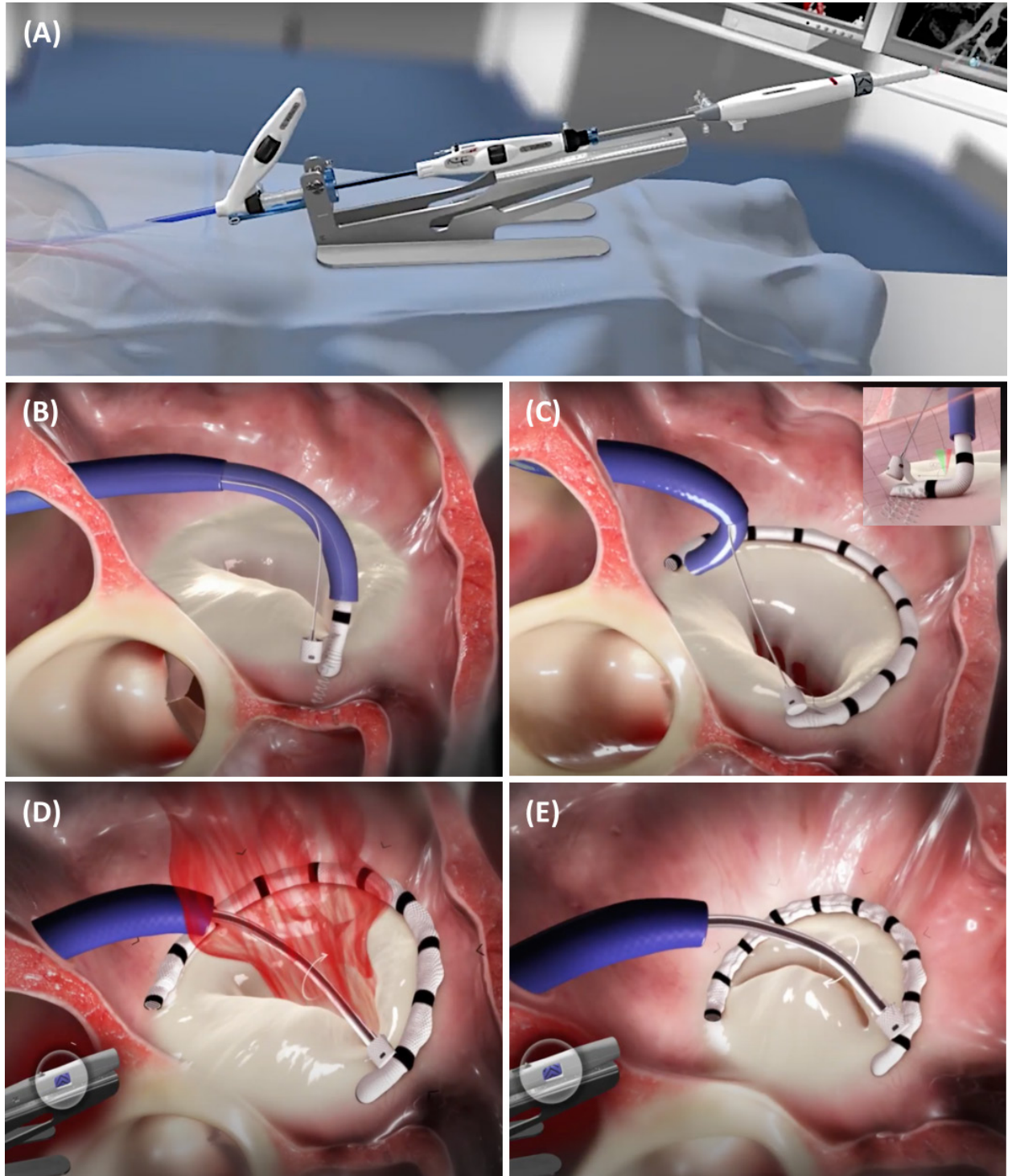

Figure 3 Cardioband Mitral System. (A) The Cardioband delivery system. (B) Correct positioning of the first anchor at the anterior and lateral side of the mitral annulus. (C) The anchors are repeatedly placed at the mitral annulus - covered by the polyester sleeve-until the implant catheter tip reaches the last anchoring site at the medial side. (D and E) Cinching of the Cardioband device, resulting in a reduction of the mitral annular diameter and mitral regurgitation severity. Images courtesy of and provided by Edwards Lifesciences.

clinical procedures ${ }^{8-10}$ and is currently enrolling in a global feasibility study.

The Millipede device has a complete semi-rigid ring design that conceptually follows the full-ring surgical predicates most commonly used as a stand-alone mitral valve repair for patients with functional MR. It has a nitinol zig-zag stent frame that is circumferentially fixed to the annulus by eight helical anchors. The top of the frame has eight slider components that can be individually cinched to achieve tailored downsizing of the mitral annulus (figure 4). The delivery catheter is designed for the transvenous transseptal delivery route and has a $27 \mathrm{Fr}$ profile.

A unique feature of the Millipede technology is the possibility of using an integrated intracardiac echocardiography catheter through the central lumen of the delivery catheter, providing unobstructed near-field imaging of the mitral annulus. This imaging modality is primarily used for control of device anchoring.

\section{Transcatheter edge-to-edge mitral valve repair}

Alfieri and colleagues first described the surgical repair of prolapse of the anterior mitral valve leaflet using an edge-to-edge technique by opposing the middle scallops of the anterior and posterior leaflets with a stitch, creating a so-called 'double-orifice' mitral valve. ${ }^{11}$ Since the Alfieri repair is acting at the leaflet level, it can be applied independently of the underlying mechanism of MR. It is the only therapy which can be effective both to degenerative and functional MR.

During the past decade, the MitraClip system (Abbott) has been increasingly adopted as a method of creating 

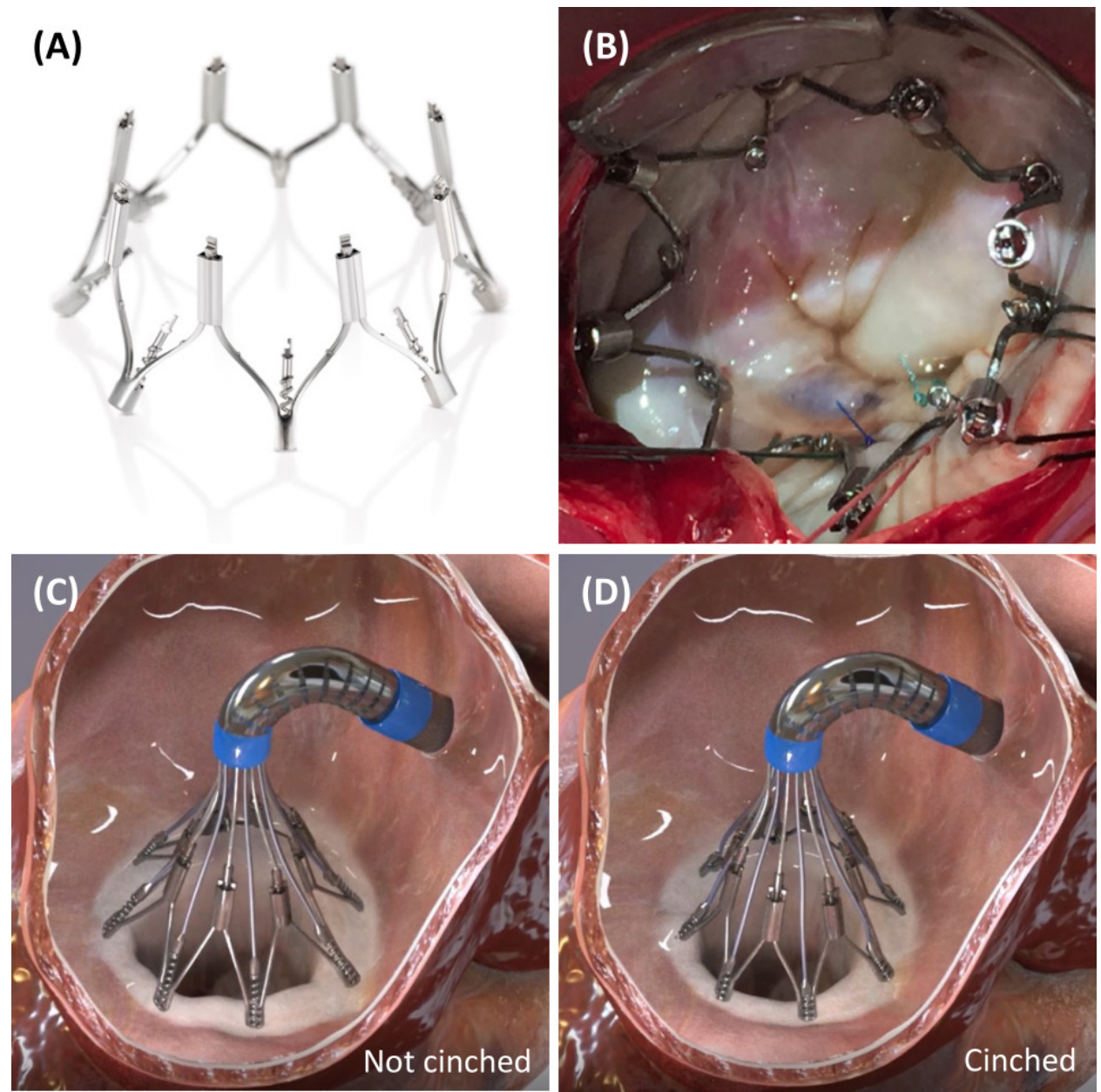

Figure 4 Millipede Transcatheter Mitral Annuloplasty System. (A and B) The Millipede device has a complete semi-rigid ring design and consists of a nitinol zig-zag stent frame that is circumferentially fixed to the annulus by eight helical anchors. (C and D) The top of the frame has eight sliders that can be individually cinched to achieve patient-tailored downsizing of the mitral annulus. Images courtesy of and provided by Boston Scientific.

an edge-to-edge mitral valve repair using a percutaneous transseptal approach. The MitraClip system received CE mark approval in 2008 and has since then known a steady growth in its use ${ }^{12-15}$; it also received Food and Drug Administration (FDA) approval for degenerative and functional MR in 2013 and 2019, respectively. It has been implanted in more than 100000 patients in over 50 countries and is the only TMVr therapy to complete prospective trials comparing the device to conventional mitral valve surgery ${ }^{1617}$ and GDMT. ${ }^{18-21}$

The PASCAL Transcatheter Valve Repair System (Edwards Lifesciences) received CE mark approval for the treatment of MR and was introduced in 2019 after showing acceptable outcomes in the CLASP study in a patient population of functional, degenerative and mixed aetiology. ${ }^{22}$

\section{MitraClip system}

The MitraClip system is a therapeutic option for patients with moderate-to-severe and severe degenerative, functional or mixed MR who are not considered suitable candidates for conventional mitral valve surgery. Some valve morphologies are more suitable for MitraClip therapy than others (see online supplemental file 1).

The MitraClip system consists of a steerable guide catheter and a clip delivery system (CDS), which includes the detachable clip. The steerable guide and CDS allow manoeuvring the clip in all different planes (figure 5A). MitraClip G4 is the 4th-generation device which comes with four enhancements. A Controlled Gripper Actuation feature allows for simultaneous or independent leaflet grasping to optimise leaflet grasping and insertion (figure 5B). MitraClip G4 also comes with the choice between four clip sizes (NT, XT, NTW, XTW) offering more options for patient-tailored TMVr (figure 5C). Integrated left atrial pressure monitoring enables real-time MR assessment. Finally, a simplified system preparation and deployment should further streamline the procedure.

The MitraClip procedure is performed under general anaesthesia using fluoroscopy and TEE guidance. The clip consists of two arms that are opened and closed by control mechanisms on the CDS and two 'grippers' that match up to each arm and help stabilising the leaflets as they are captured during closure of the clip arms. Leaflet 


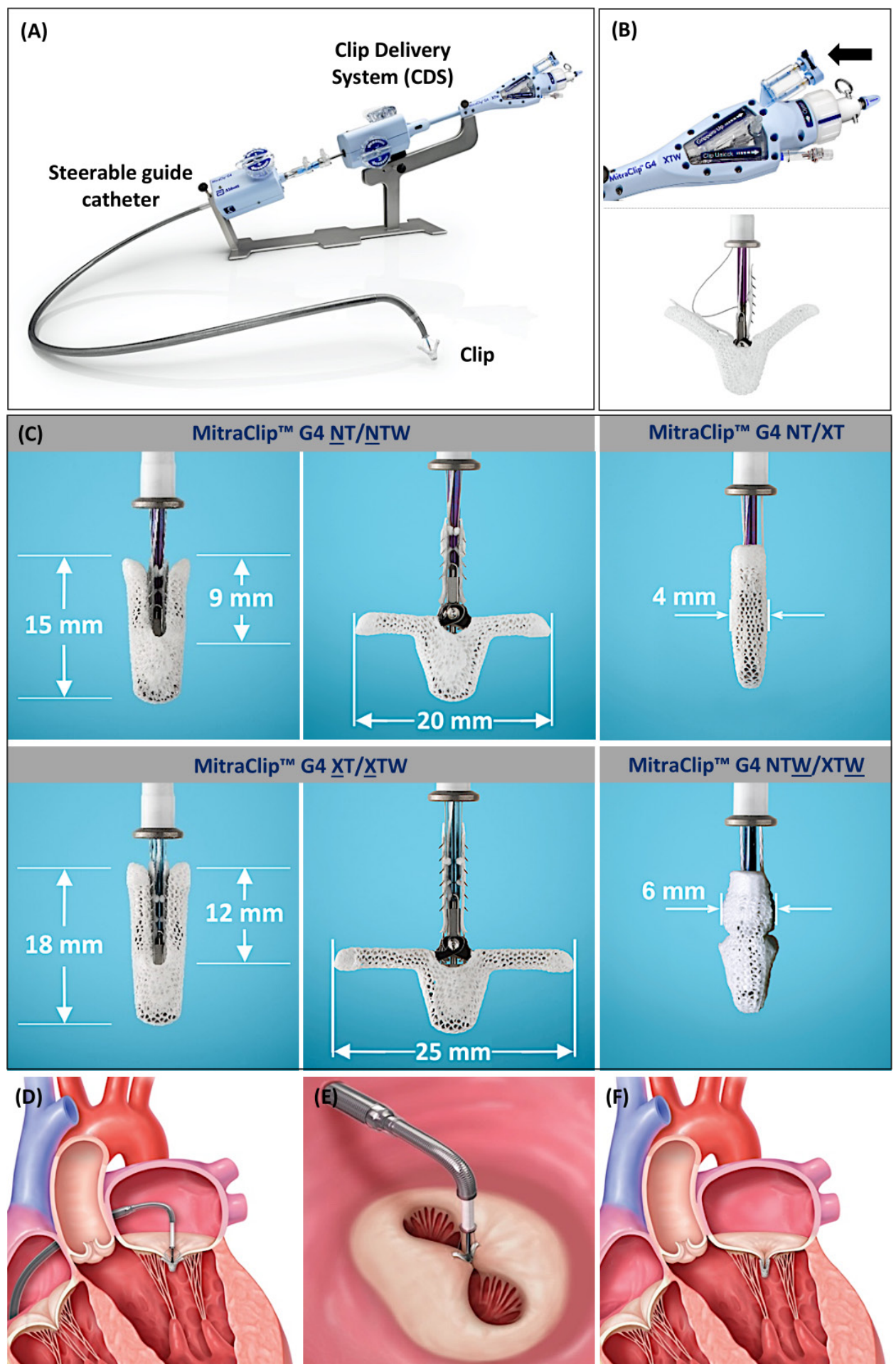

Figure 5 MitraClip G4 System. (A) All components of the new-generation MitraClip G4 System. (B) Two independent gripper levers allow for independent grasping of the mitral leaflets. (C) The MitraClip G4 includes four clip sizes (NT, XT, NTW and XTW) offering more options for patient-tailored mitral valve repair. (D) After steering the clip above the mitral valve and opening the clip arms, the clip is passed across the mitral leaflets into the left ventricle, the clip is gently pulled back and the leaflets are grasped by the grippers. (E) Next, the clip is closed and a double orifice mitral valve opening can be seen by 3D-TEE surgeon's view. (F) Final result after MitraClip implantation with approximation of the anterior and posterior mitral leaflets and reduction of the mitral regurgitation. Images courtesy of and provided by Abbott.

tissue is secured between the arms and each side of the gripper, and the clip is then closed and locked to maintain leaflet coaptation. Prior to clip deployment, a leaflet insertion and haemodynamic assessment should be performed (figure 5D-F). Pressure gradients are assessed to ensure there is no clip-induced mitral stenosis. If needed, the physician may also place a second or third clip to optimise MR reduction. 
MitraClip is supported by the largest body of evidence of all TMVr therapies. More than 30000 patients have been treated in MitraClip clinical trials representing 16 years of clinical research published in more than 2050 scientific papers. An overview of key MitraClip studies can be found in online supplemental file 2.

Results of two RCTs comparing MitraClip with GDMT-MITRA-FR ${ }^{18}$ and COAPT ${ }^{20}$-in patients with functional MR became available in 2018, with 2-year and 3-year follow-up data released in 2019 and 2020, respectively. ${ }^{19}{ }^{21}$ The RCT findings were conflicting, with the MITRA-FR study showing no benefit on the primary endpoint at 1 year (composite of death or rehospitalisation for heart failure), while the COAPT study showed positive results on the primary endpoint at 2 years (cumulative rate of rehospitalisation for heart failure) as well as on all-cause mortality. These different outcomes observed in both RCTs may be explained by the following aspects: (1) COAPT enrolled a subset of patients who had more severe MR and less LV dilation compared with MITRA-FR patients; (2) the GDMT used in the two trials differed-the rates of drug use and medication titration throughout the MITRA-FR trial course were not tracked, and although guideline-directed, they may not have been guideline optimised; (3) technical success was different between the two trials-residual MR class $\geq 3+$ was higher post-MitraClip in the MITRA-FR as compared with the COAPT trial, both acutely (9\% vs 5\%) and at 12 months (17\% vs $5 \%)$. Taken together, it may be concluded that MitraClip therapy seems to give the best result for patients with severe MR and less advanced LV dilatation and when MR reduction can be obtained. Under these conditions, the MitraClip system is the only TMVr device to show improved survival in heart failure patients with functional MR. ${ }^{18-21} 23-25$

\section{PASCAL Transcatheter Valve Repair System}

The PASCAL Transcatheter Valve Repair System consists of a guide sheath, steerable sheath and implant catheter which includes the PASCAL or PASCAL Ace implant. The ability to independently move these catheters allows manoeuvring in three different planes; intending to assist the operator in the treatment of challenging anatomies. The PASCAL $(10 \mathrm{~mm}$ width) and PASCAL Ace $(6 \mathrm{~mm}$ width) implants consist of two paddles, two clasps and a central spacer: (1) the two paddles promote leaflet approximation; (2) the two clasps allow for independent leaflet capture and adjustment of leaflet insertion-a clasp only has 1 row of grippers versus 4-6 rows in grippers in the MitraClip system and (3) the central spacer should reduce the tension on the leaflets and fill the regurgitant orifice area to minimise MR. A feature of the PASCAL implant is its ability to elongate, which promotes safe retraction from the subvalvular apparatus, thereby reducing the risk of damaging the chords (figure 6). The procedure is performed under general anaesthesia using fluoroscopy and TEE guidance and follows the same procedural steps as a MitraClip procedure.
The PASCAL System received CE mark approval for the treatment of MR after showing acceptable safety and feasibility in the CLASP study in a patient population of functional, degenerative and mixed aetiology. The procedural and clinical success rate was $92 \%$ and $87 \%$, respectively. There was reduction of MR grade $3 / 4+$ at baseline to MR grade $\leq 2$ in $98 \%$ of patients and to MR grade $\leq 1$ in $86 \%$ of patients at 30 days. ${ }^{22}{ }^{26}$ One-year outcomes of the CLASP study demonstrated a high survival rate of $92 \%$ for the overall population and $89 \%$ and $96 \%$ for the functional and degenerative MR populations, respectively. There was evidence of sustained MR reduction with $82 \%$ of patients having MR grade $\leq 1 \%$ and $100 \%$ having MR grade $\leq 2$. Improvement in exercise capacity and quality of life were also significant at 1 year. ${ }^{27}$

The PASCAL Transcatheter Valve Repair System and MitraClip System are being compared in patients with both degenerative and functional MR within the CLASPIID/IIF Pivotal Clinical Trial (ClinTrials.Gov: NCT03706833).

\section{Transcatheter mitral valve chordal repair}

Transcatheter mitral valve chordal repair systems have been developed to treat severe degenerative MR due to a prolapse or flail posterior, anterior or both mitral valve leaflets. The two systems that are currently under investigation in an FDA Pivotal and CE Mark trial are the NeoChord Artificial Chordae Delivery System (NeoChord, Minnesota, USA) and HARPOON Mitral Valve Repair System (MVRS; Edwards Lifesciences), respectively. Both systems are designed for transapical, beating heart, off-pump mitral valve repair and require a left lateral thoracotomy incision.

\section{NeoChord}

NeoChord implantation is currently indicated for severe degenerative MR due to a prolapse or flail posterior, anterior or both mitral valve leaflets. Patients with a central posterior leaflet (P2) prolapse or frail are the best candidates for NeoChord treatment; it should also be performed at an early stage of mitral valve pathology, before annular dilatation occurs. ${ }^{28} 29$

The procedure is performed under general anaesthesia with intraprocedural TEE guidance. Following a standard left lateral mini thoracotomy, the apical access site should be confirmed by real-time 2D-TEE imaging using gentle 'finger poking' approximately $2-3 \mathrm{~cm}$ lateral from the true LV apex (figure 7A,B). Correct localisation of the ideal entry site allows the operator to navigate the device towards the mitral valve while maintaining a correct alignment and without interfering with the subvalvular apparatus. When an appropriate position of the device is reached, the jaws of the device are opened (figure 7C), and the leaflet edge is grasped by withdrawing the device from the left atrium. A loop of the suture and a girth hitch knot can then be formed through the mitral leaflet (figure 7D,E). The device can be reloaded with a new suture and the procedure can be repeated until enough 


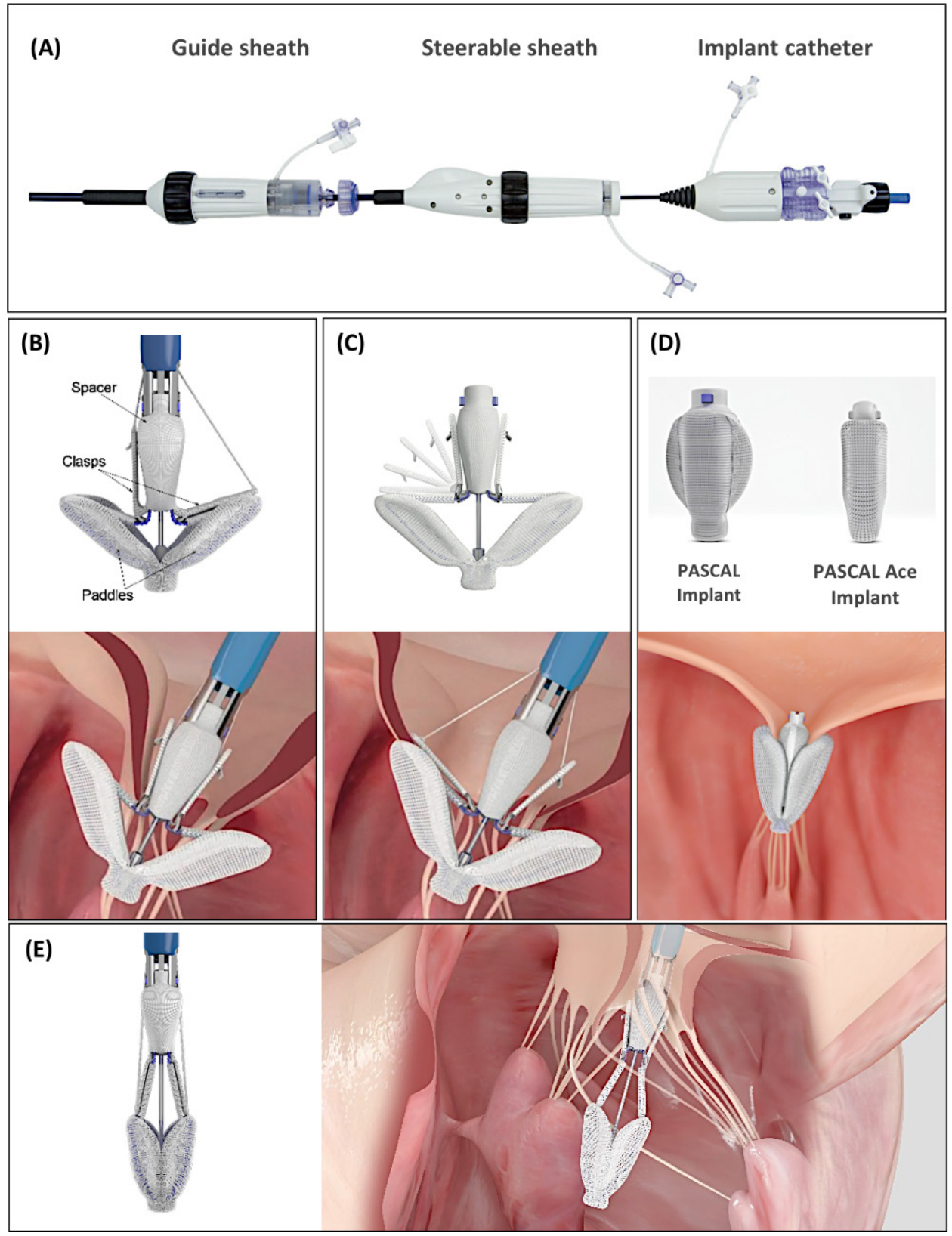

Figure 6 PASCAL Transcatheter Valve Repair System. (A) The three components of the PASCAL delivery system. (B) The PASCAL implant consists of two paddles, two clasps and a central spacer. (C) Independent leaflet capture should enable operators to adjust leaflet insertion and capture leaflets in difficult pathologies. (D) The newest generation PASCAL Ace implant has $6 \mathrm{~mm}$ wide paddles and a smaller spacer that fills the regurgitant orifice and reduces the leaflet approximation distance. (E) Elongation of the PASCAL device facilitates retraction of the device from the left ventricle, if needed, with a reduced risk of getting entangled in the chords. Images courtesy of and provided by Edwards Lifesciences.

neo-chordae have been implanted; usually 3-4 neochordae are implanted. The length of each neo-chordae can be adjusted to achieve maximal MR reduction under normal LV filling conditions (figure 7F,G). Each of the neo-chordae can then be tied to the LV epicardial pledget (figure $7 \mathrm{H}$ ).

The Trans-Apical Chordae Tendineae trial showed satisfying immediate safety and efficacy of the NeoChord system, leading to CE approval. ${ }^{30}$ The ongoing AcChord Registry will provide more long-term outcome data in a post-market setting. The RECHORD trial (ClinicalTrials.gov: NCT02803957) is an ongoing prospective, multicentre, randomised FDA pivotal trial intended to establish the safety and effectiveness of the device as an alternative to standard surgical mitral valve repair. The company is currently working on a fully percutaneous transseptal system, which is at the moment under preclinical evaluation.

\section{HARPOON MVRS}

The HARPOON Beating Heart MVRS is intended to reduce the degree of MR in patients with severe degenerative MR caused by posterior mitral leaflet prolapse by delivering and anchoring e-polytetrafluoroethylene 

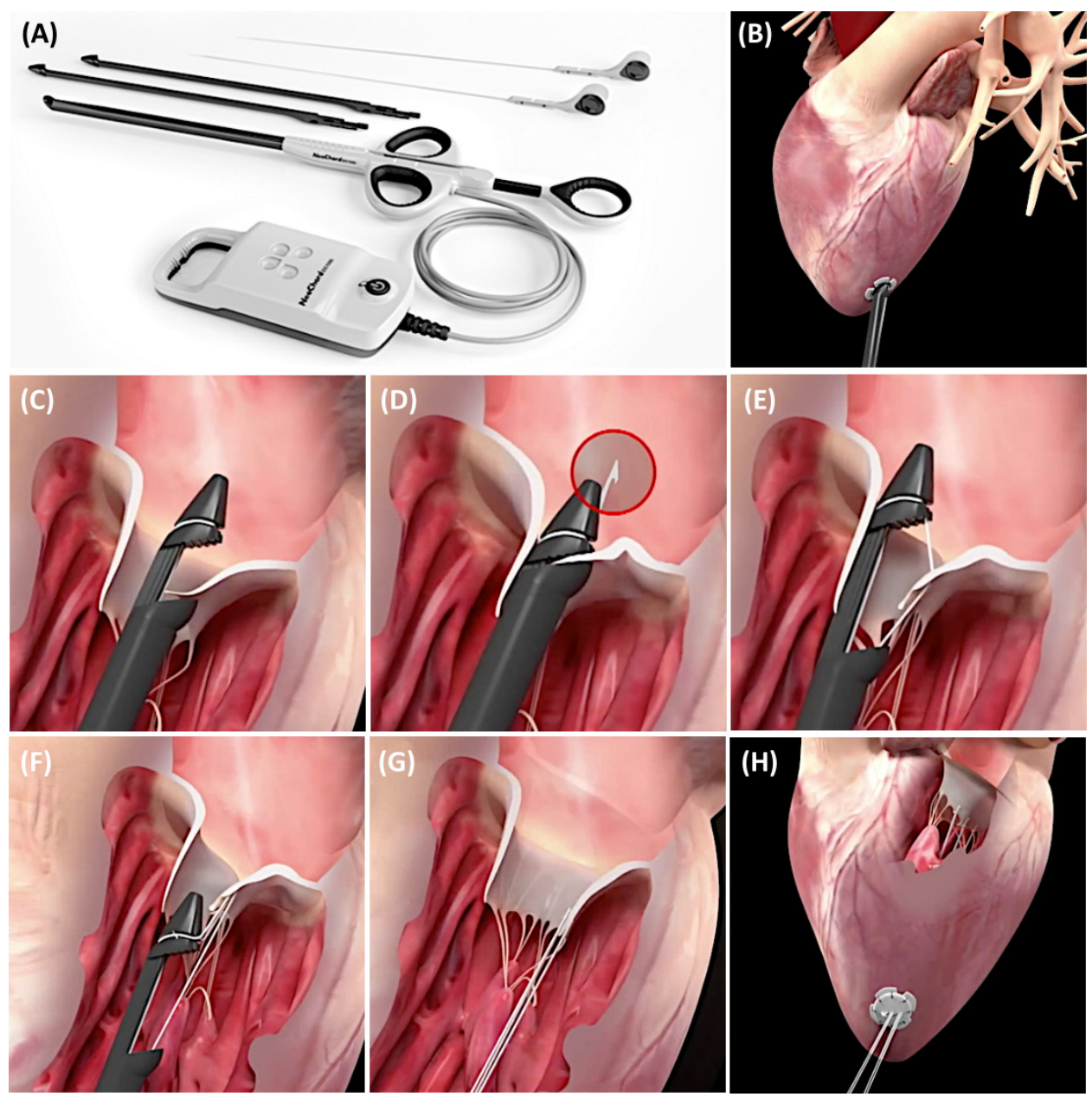

Figure 7 NeoChord Transcatheter Mitral Valve Repair. (A) Components of the NeoChord system. (B) NeoChord is a transapical, beating heart, off-pump mitral valve repair system. (C) The jaws of the device are opened and the leaflet edge is grasped by withdrawing the device from the left atrium. ( $D$ and $E$ ) A loop of the suture and a girth hitch knot can be formed through the mitral leaflet. ( $F$ and $G$ ) The length of each neo-chordae can be adjusted to achieve maximal mitral regurgitation reduction under normal left ventricular (LV) filling conditions as assessed by transesophageal echocardiography. (H) Each of the neo-chordae is tied to the LV epicardial pledget. Images courtesy of and provided by NeoChord.

(ePTFE) chords to the prolapsed mitral valve leaflet in a beating heart.

The procedure is performed under general anaesthesia using a left lateral thoracotomy incision (figure 8A). As soon as TEE confirms that the delivery system does not move and that the end effector stays in contact with the targeted site on the mitral leaflet, the plunger is released to deploy a double-helical knot through the free-edge of the leaflet (figure 8B-D). These steps are repeated until the desired number of ePTFE chords have been implanted starting from a lateral to medial target location. Next, all ePTFE chords are passed through a stiff Teflon pledget and simultaneously tensioned. While observing the cardiac cycles in X-plane 3D-TEE, the sutures are adjusted one at a time to obtain the desired leaflet coaptation (figure 8E).

The Early Feasibility Study and CE Mark TRACER trial investigated the early feasibility and safety of treatment with the HARPOON system in 13 and 52 patients, respectively. ${ }^{31-33}$ Of 65 patients enrolled in the two studies, 62 $(95 \%)$ achieved technical success, 2 patients required conversion to open surgery and one procedure was terminated. The primary endpoint was met in $91 \%$ of patients. ${ }^{32}$ At 1 year of follow-up, $98 \%$ of patients were in NYHA Class $\leq \mathrm{II}$; MR was $\leq$ mild in $75 \%$ and $\leq$ moderate in $98 \%$ of patients. ${ }^{33}$

In Europe, Post-Market Clinical Follow-Up trials are currently underway and will collect additional safety and device performance data on the HARPOON MVRS in patients with severe degenerative MR. The RESTORE IDE pivotal trial (ClinTrials.Gov: NCT04375332) is being initiated in North-America to evaluate the safety and effectiveness of the HARPOON MVRS in patients with severe degenerative MR presenting with mid-segment posterior mitral leaflet prolapse.

\section{CONCLUSION}

TMVr represents a wide spectrum of percutaneous treatment modalities targeting different parts of the mitral apparatus (mitral annulus, mitral valve leaflets and mitral valve chordae). These modalities should be regarded 

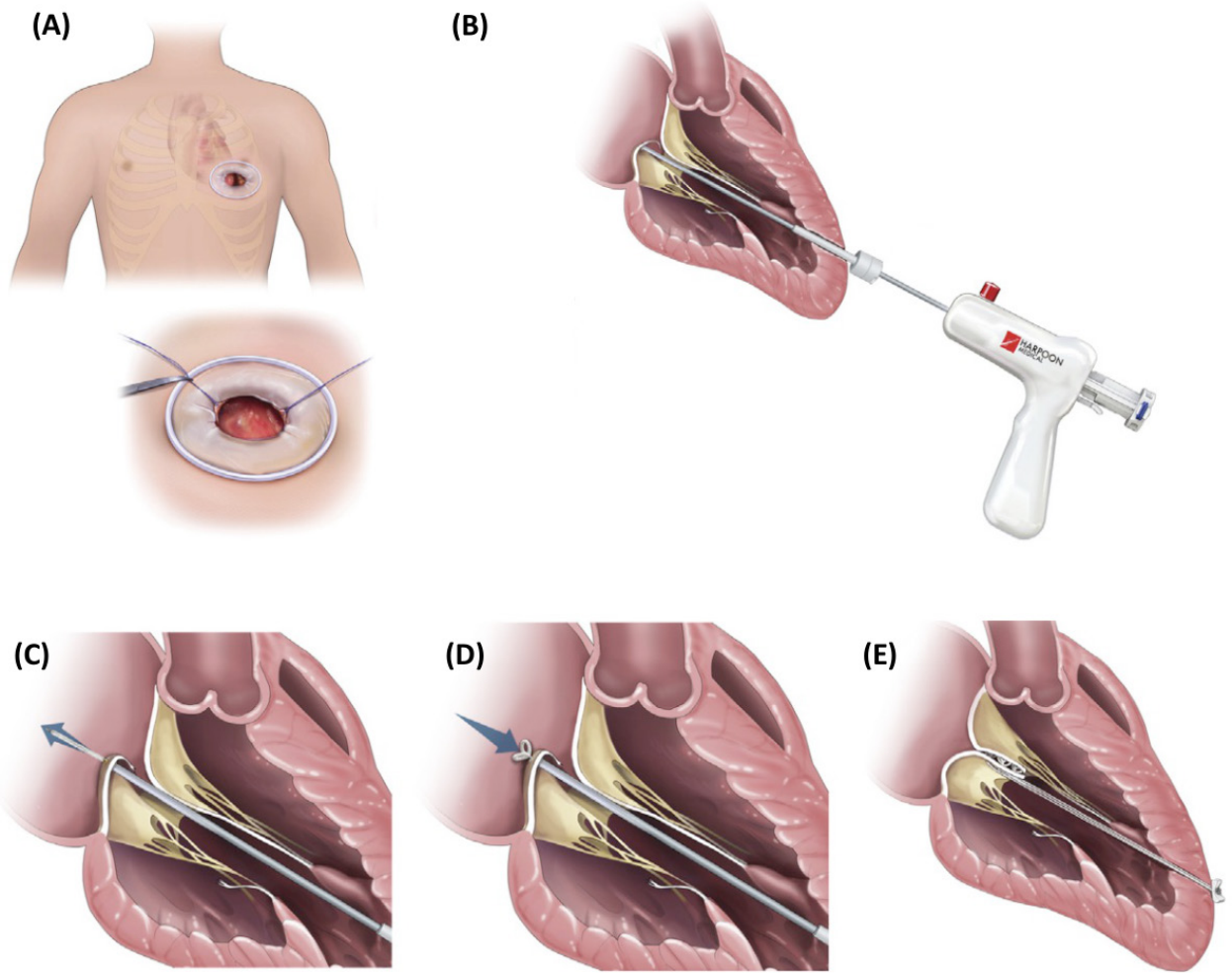

Figure 8 HARPOON Mitral Valve Repair System. (A) The procedure is performed through a left lateral thoracotomy incision overlying the left ventricular (LV) apex. (B) Components of the HARPOON System: introducer and delivery system. HARPOON is a transapical, beating heart, off-pump mitral valve repair system. (C-E) Deployment of a double-helical knot through the free-edge of the leaflet and e-polytetrafluoroethylene chordal tensioning until the desired level of leaflet coaptation is obtained. Images courtesy of and provided by Edwards Lifesciences.

as complementary rather than competing in their goal to reduce MR, which itself not rarely has complex and multiple aetiologies. With further data from ongoing clinical studies to be expected, consensus in the Heart Team approach is needed to address these complexities and to determine the most appropriate TMVr therapy, either isolated or combined, for patients with severe symptomatic MR.

Twitter Ivan Wong @ivanwongm12

Contributors ODB and IW collected all data and information and wrote the first draft. All other coauthors critically reviewed the manuscript.

Funding The authors have not declared a specific grant for this research from any funding agency in the public, commercial or not-for-profit sectors.

Competing interests $\mathrm{ODB}$ received institutional research grants and consulting fees from Abbott and Boston Scientific. MT is a consultant for Abbott Vascular, Boston Scientific and 4tech; received personal fees from Edwards Lifesciences, Mitraltech, CoreMedic and Swissvortex; and is a shareholder of 4Tech. FM obtained grant and/or research institutional support from Abbott, Medtronic, Edwards Lifesciences, Biotronik, Boston Scientific Corporation, NVT, Terumo, Consulting fees, Honoraria personal and institutional from Abbott, Medtronic, Edwards Lifesciences, Xeltis, Cardiovalve, Occlufit, Simulands, Occlufit; has Royalty Income/IP Rights Edwards Lifesciences; and is shareholder (including share options) of Cardiogard, Magenta, SwissVortex, Transseptal solutions, Occlufit, 4Tech, Perifect. LS received institutional research grants and consulting fees from Abbott, Boston Scientific, Medtronic and Edwards Lifesciences. All other coauthors have no conflict of interest to disclose concerning this manuscript.

Patient consent for publication Not required.

Provenance and peer review Not commissioned; externally peer reviewed. Data availability statement No data are available.
Open access This is an open access article distributed in accordance with the Creative Commons Attribution Non Commercial (CC BY-NC 4.0) license, which permits others to distribute, remix, adapt, build upon this work non-commercially, and license their derivative works on different terms, provided the original work is properly cited, appropriate credit is given, any changes made indicated, and the use is non-commercial. See: http://creativecommons.org/licenses/by-nc/4.0/.

Correction notice Since the publication of this article, the authors have noticed that in the caption of Figure 8, the system name was incorrect in two instances. 'NeoChord' has been corrected to 'HARPOON'.

ORCID iD

Ole De Backer http://orcid.org/0000-0002-9674-0278

\section{REFERENCES}

1 Witte KK, Lipiecki J, Siminiak T, et al. The REDUCE FMR trial: a randomized sham-controlled study of percutaneous mitral annuloplasty in functional mitral regurgitation. JACC Heart Fail 2019;7:945-55.

2 Lipiecki J, Kaye DM, Witte KK, et al. Long-term survival following transcatheter mitral valve repair: pooled analysis of prospective trials with the Carillon device. Cardiovasc Revasc Med 2020;21:712-6.

3 Rogers $\mathrm{JH}$, Thomas M, Morice $\mathrm{M}-\mathrm{C}$, et al. Treatment of heart failure with associated functional mitral regurgitation using the ARTO system: initial results of the first-in-human MAVERIC trial (mitral valve repair clinical trial). JACC Cardiovasc Interv 2015;8:1095-104.

4 Erglis A, Thomas M, Morice M-C, et al. The ARTO transcatheter mitral valve repair system. Eurolntervention 2015;11 Suppl W:W47-8.

5 Erglis A, Narbute I, Poupineau M, et al. Treatment of secondary mitral regurgitation in chronic heart failure. J Am Coll Cardiol 2017;70:2834-5.

6 Worthley S, Redwood S, Hildick-Smith D, et al. Transcatheter reshaping of the mitral annulus in patients with functional 
mitral regurgitation: one-year outcomes of the MAVERIC trial. Eurolntervention 2021;16:1106-13.

7 Messika-Zeitoun D, Nickenig G, Latib A, et al. Transcatheter mitral valve repair for functional mitral regurgitation using the Cardioband system: 1 year outcomes. Eur Heart J 2019;40:466-72.

8 Rogers JH, Boyd WD, Smith TW, et al. Transcatheter mitral valve direct Annuloplasty with the millipede iris ring. Interv Cardiol Clin 2019;8:261-7.

9 Rogers JH, Boyd WD, Smith TW, et al. Early experience with millipede iris transcatheter mitral annuloplasty. Ann Cardiothorac Surg 2018;7:780-6.

10 Rogers JH, Boyd WD, Smith TWR, et al. Transcatheter annuloplasty for mitral regurgitation with an adjustable semi-rigid complete ring: initial experience with the millipede iris device. Structural Heart 2018;2:43-50.

11 Alfieri O, De Bonis M, Lapenna E, et al. "Edge-to-edge" repair for anterior mitral leaflet prolapse. Semin Thorac Cardiovasc Surg 2004;16:182-7.

12 Franzen O, Baldus S, Rudolph V, et al. Acute outcomes of MitraClip therapy for mitral regurgitation in high-surgical-risk patients: emphasis on adverse valve morphology and severe left ventricular dysfunction. Eur Heart J 2010;31:1373-81.

13 Rogers JH, Franzen O. Percutaneous edge-to-edge MitraClip therapy in the management of mitral regurgitation. Eur Heart $J$ 2011;32:2350-7.

14 Rudolph V, Knap M, Franzen O, et al. Echocardiographic and clinical outcomes of MitraClip therapy in patients not amenable to surgery. $J$ Am Coll Cardiol 2011:58:2190-5.

15 Maisano F, Godino C, Giacomini A, et al. Clinical trial experience with the MitraClip catheter based mitral valve repair system. Int $J$ Cardiovasc Imaging 2011;27:1155-64.

16 Feldman T, Foster E, Glower DD, et al. Percutaneous repair or surgery for mitral regurgitation. N Engl J Med 2011;364:1395-406.

17 Feldman T, Kar S, Elmariah S, et al. Randomized comparison of percutaneous repair and surgery for mitral regurgitation: 5-year results of Everest II. J Am Coll Cardiol 2015;66:2844-54.

18 Obadia J-F, Messika-Zeitoun D, Leurent G, et al. Percutaneous repair or medical treatment for secondary mitral regurgitation. $N$ Engl $J$ Med 2018;379:2297-306.

19 lung B, Armoiry X, Vahanian A, et al. Percutaneous repair or medical treatment for secondary mitral regurgitation: outcomes at 2 years. Eur J Heart Fail 2019;21:1619-27.

20 Stone GW, Lindenfeld J, Abraham WT, et al. Transcatheter mitral-valve repair in patients with heart failure. N Engl $\mathrm{J} \mathrm{Med}$ 2018;379:2307-18.
21 Mack M, Abraham WT, Lindenfeld J. Three-year outcomes from a randomized trial of transcatheter mitral valve leaflet approximation in patients with heart failure and secondary mitral regurgitation. Presented at TCT; Sept 25-29, San Francisco, 2019.

22 Lim DS, Kar S, Spargias K, et al. Transcatheter valve repair for patients with mitral regurgitation: 30 -day results of the CLASP study. JACC Cardiovasc Interv 2019;12:1369-78.

23 Al-Azizi K. The COAPT trial: outcomes of transcatheter mitral valve repair in ischemic versus Non-ischemic cardiomyopathy. Presented at ACC.20/WCC Virtual, 2020

24 Lerakis S, Kini AS, Kar S. Outcomes of transcatheter mitral valve repair in patients with secondary mitral regurgitation according to the severity of left ventricular dysfunction: the COAPT trial. Presented at ACC.20/WCC Virtual, 2020

25 Arnold SV. Short-Term health status changes and long-term outcomes in patients with heart failure and mitral regurgitation: results from the COAPT trial. Presented at ACC.20/WCC Virtual, 2020.

26 Praz F, Spargias K, Chrissoheris M, et al. Compassionate use of the PASCAL transcatheter mitral valve repair system for patients with severe mitral regurgitation: a multicentre, prospective, observational, first-in-man study. Lancet 2017;390:773-80.

27 Webb JG, Hensey M, Szerlip M, et al. 1-year outcomes for transcatheter repair in patients with mitral regurgitation from the clasp study. JACC Cardiovasc Interv 2020;13:2344-57.

28 Colli A, Manzan E, Zucchetta F, et al. Transapical off-pump mitral valve repair with Neochord implantation: early clinical results. Int $J$ Cardiol 2016;204:23-8.

29 Colli A, Adams D, Fiocco A, et al. Transapical NeoChord mitral valve repair. Ann Cardiothorac Surg 2018;7:812-20.

30 Seeburger J, Rinaldi M, Nielsen SL, et al. Off-pump transapical implantation of artificial neo-chordae to correct mitral regurgitation: the TACT trial (Transapical artificial chordae Tendinae) proof of concept. J Am Coll Cardiol 2014;63:914-9.

31 Gammie JS, Wilson P, Bartus K, et al. Transapical beating-heart mitral valve repair with an expanded polytetrafluoroethylene Cordal implantation device: initial clinical experience. Circulation 2016;134:189-97.

32 Gammie JS, Bartus K, Gackowski A, et al. Beating-heart mitral valve repair using a novel ePTFE cordal implantation device: a prospective trial. J Am Coll Cardiol 2018;71:25-36.

33 Gammie JS, Bartus K, Gackowski A, et al. Safety and performance of a novel transventricular beating heart mitral valve repair system: 1-year outcomes. Eur J Cardiothorac Surg 2021;59:199-206. 


\section{Correction: Transcatheter mitral valve repair: an overview of current and future devices}

De Backer O, Wong I, Taramasso M, et al. Transcatheter mitral valve repair: an overview of current and future devices. Open Heart 2021;8:e001564. doi: 10.1136/ openhrt-2020-001564

Since the publication of this article, the authors have noticed that in the caption of Figure 8, the system name was incorrect in two instances. 'NeoChord' has been corrected to 'HARPOON'.

Open access This is an open access article distributed in accordance with the Creative Commons Attribution Non Commercial (CC BY-NC 4.0) license, which permits others to distribute, remix, adapt, build upon this work non-commercially, and license their derivative works on different terms, provided the original work is properly cited, appropriate credit is given, any changes made indicated, and the use is non-commercial. See: http://creativecommons.org/licenses/by-nc/4.0/.

(C) Author(s) (or their employer(s)) 2021. Re-use permitted under CC BY-NC. No commercial re-use. See rights and permissions. Published by BMJ.

Open Heart 2021;8:e001564corr1. doi:10.1136/openhrt-2020-001564corr1

A) Check for updates 